\title{
Incidence of Vitamin D Deficiency and Its Relevance to Bone Metabolism in Japanese Postmenopausal Women with Type 2 Diabetes Mellitus
}

\author{
Hiroko Mori, Yosuke Okada and Yoshiya Tanaka
}

\begin{abstract}
Objective The aim of this study was to assess the incidence of vitamin D deficiency in Japanese postmenopausal women with type 2 diabetes mellitus.

Methods Serum 25-hydroxyvitamin D [25(OH)D], intact-parathyroid hormone (PTH), and various bone markers were measured. The primary outcome was the serum level of 25(OH)D.

Patients This study included postmenopausal women with type 2 diabetes mellitus.

Results The study patients included 170 women with a mean $25(\mathrm{OH}) \mathrm{D}$ of $20.0 \mathrm{ng} / \mathrm{mL}$. With regard to the serum level of $25(\mathrm{OH}) \mathrm{D}$, the patients were defined as normal $(\geq 30 \mathrm{ng} / \mathrm{mL}, 8.2 \%$ of the patients) and abnormal $(<30 \mathrm{ng} / \mathrm{mL}, 91.8 \%$ of the patients, vitamin D deficiency). The latter group was subdivided into severe deficiency $(<10 \mathrm{ng} / \mathrm{mL}, 2.9 \%$ of the patients), deficiency $(10-19 \mathrm{ng} / \mathrm{mL}, 47.1 \%$ of the patients), and insufficiency $(20-29 \mathrm{ng} / \mathrm{mL}, 41.8 \%$ of the patients). There was a significant negative correlation between the serum 25(OH)D level with type I collagen cross-linked N-telopeptides (NTX) and intact-PTH, but not between 25 $(\mathrm{OH}) \mathrm{D}$ and the bone quality markers. There was a significant positive correlation between $25(\mathrm{OH}) \mathrm{D}$ and the radial bone mineral density, but not between $25(\mathrm{OH}) \mathrm{D}$ and the bone mineral density on the lumbar vertebrae and femur. A multivariate analysis identified NTX as the only significant determinant of $25(\mathrm{OH}) \mathrm{D}$. The cutoff value of $25(\mathrm{OH}) \mathrm{D}$ was $18.5 \mathrm{ng} / \mathrm{mL}$ based on a Receiver Operatorating Characteristic analysis.

Conclusion Our results showed an alarmingly high incidence of vitamin D deficiency in Japanese women with type 2 diabetes mellitus, with a risk of radial bone osteoporosis, particularly in those patients with a serum $25(\mathrm{OH}) \mathrm{D}$ level of $<18.5 \mathrm{ng} / \mathrm{mL}$.
\end{abstract}

Key words: vitamin D, postmenopausal, type 2 diabetes

(Intern Med 54: 1599-1604, 2015)

(DOI: 10.2169/internalmedicine.54.3638)

\section{Introduction}

Type 2 diabetes mellitus is a major lifestyle disease, a category in which osteoporosis has also been included recently. The healing of bone fractures is often delayed in the patients with type 2 diabetes mellitus. Therefore, the prediction and early intervention of osteoporosis is important in diabetes-related disorders. A meta-analysis study showed that the risk of femoral neck fracture is increased by 1.38 (1.25 to 1.53$)$ in the patients with type 2 diabetes mellitus (1). Because type 2 diabetes mellitus can increase the risk of bone fracture as a result of osteoporosis (2), the importance of the management of osteoporosis has been highlighted in recent years. However, the true picture of diabetes-associated abnormalities of bone metabolism remains unclear.

Vitamin D plays an important role in bone health, and vitamin D deficiency is associated with decreased bone mineralization, secondary hyperparathyroidism, and increased cortical bone loss. Furthermore, hypovitaminosis D has been linked to the pathogenesis of osteoporosis and hip fractures (3). Vitamin D deficiency additionally increases the risk of type 2 diabetes mellitus as well as the risk of falls 
and fractures. Previous studies have reported a widespread rate of vitamin D deficiency in the general population (4), however, few have reported the vitamin D status in type 2 diabetes mellitus.

The erum levels of 25-hydroxy vitamin D [25(OH)D] are an accepted measure of the vitamin D status, regardless of the source of vitamin D. The present study is designed to determine the incidence of vitamin D deficiency in Japanese patients with type 2 diabetes mellitus. For this purpose, we measure the serum concentrations of $25(\mathrm{OH}) \mathrm{D}$ and evaluate the potential relationship between vitamin D insufficiency and osteoporosis.

\section{Materials and Methods}

\section{Study design and population}

This study was cross-sectional in design and included women with type 2 diabetes mellitus who were treated at the Outpatient Department of the University of Occupational and Environmental Health Hospital or its affiliated hospitals between September 2009 and October 2010. The patients with a history of ketoacidosis, type 1 diabetes mellitus, nephropathy (serum creatinine level $>2.0 \mathrm{mg} / \mathrm{dL}$ ), women who were pregnant or possibly pregnant, and the patients receiving any drugs that are known to affect bone metabolism (e.g., bisphosphonates, vitamin $\mathrm{K}$, estrogen, calcium, anabolic steroids, or male/female hormones) were excluded from the study. The study protocol was approved by the ethics committees of the University of Occupational and Environmental Health, Japan and participating medical centers. Informed consent was obtained from each study subject.

Venous blood and urine samples were obtained in the morning following an overnight fast. The following parameters were evaluated: $25(\mathrm{OH}) \mathrm{D}, 1.25$-dihydroxy vitamin $\mathrm{D}$ $\left[1.25(\mathrm{OH})_{2} \mathrm{VD}\right]$, intact-parathyroid hormone (PTH), bonespecific alkaline phosphatase (BAP), osteocalcin (OC), serum and urine N-terminal telopeptide of type I collagen (NTX), homocysteine, pentosidine and the bone mineral density (BMD) at the lumbar vertebrae (L2-4), femoral neck and radius by dual-energy X-ray absorptiometry (DEXA) using a Hologic Delphi A Densitometer. 25(OH)D and 1.25 $(\mathrm{OH})_{2} \mathrm{VD}$ was measured using a radioimmunoassay (25HydroxyvitaminD ${ }^{125}$ I RIA KIT, Dia Sorin Inc., Stillwater, USA, $\gamma$ counter, Hitachi-Aloka Medical, Mitaka, Japan, and 1.25(OH)2D RIA KIT, Immunodiagnostic System, Boldon, UK, $\gamma$ counter, Hitachi-Aloka Medical). BAP was measured using an enzyme immunoassay technique (Osteolinks BAP, Quidel Corporation, San Diego, USA, and fully automated EIA apparatus, Nippon Advanced Technology, Naka-gun, Japan), OC was determined using a radioimmunoassay (BGP IRMA, Mitsubishi Chemical Medience, Chiyoda-ku, Japan, $\gamma$ counter, Warack) and NTX was determined using an enzyme-linked immunosorbent assay kit (Osteomark NTX, Inverness Medical Japan, Shinjuku-ku, Japan, fully automated EIA apparatus, and Nippon Advanced Technology).
As a measure of the bone quality, homocysteine was determined using high-performance liquid chromatography (YMC-Pack Pro C18, YMC, Shimogyo-ku, Japan, HPLC system/Shimadzu, Hitachi, JASCO, Daito-ku, Japan) and pentosidine was determined using an enzyme-linked immunosorbent assay kit (FSK pentosidine, Fushimi Pharmaceutical, Marugame, Japan, Benchmark 1575 Microplate Reader, Sakura Seiki, Tokyo, Japan). The value of HbA1c $(\%)$ was estimated as an NGSP equivalent value (\%) derived from the JDS value and calculated by the formula: HbA1c $(\%)=$ HbA1c $($ JDS $)(\%)+0.4 \%(5)$. All other biochemical parameters were measured by the standard enzymatic methods.

The primary outcome of the study was the serum level of $25(\mathrm{OH}) \mathrm{D}$. The secondary outcome of the study was the relationship between $25(\mathrm{OH}) \mathrm{D}$ and the BMD.

\section{Statistical analysis}

The patients with an estimated glomerular filtration rate (eGFR) of $60 \mathrm{~mL} / \mathrm{min} / 1.7 \mathrm{~m}^{2}$ or below were excluded from the study in order to eliminate the effect of chronic kidney disease (CKD) on NTX and 25(OH)D. In addition, premenopausal women were also excluded from the study to avoid any confounding effects of menopause.

The data are expressed as the mean \pm SD. The Wilcoxon rank sum test was used for comparison of the groups. A correlation analysis was performed with the use of Spearman's rank correlation coefficients for the variables with a skewed distribution. A multivariate stepwise regression analysis was conducted using $25(\mathrm{OH}) \mathrm{D}$ as the dependent variable and several parameters found to be significantly related to $25(\mathrm{OH}) \mathrm{D}$ on a univariate analysis. The optimal cutoff value of $25(\mathrm{OH}) \mathrm{D}$ was determined using a receiver operating characteristics curve (ROC). Statistical significance was considered to exist at $\mathrm{p}$ values less than 0.05 . All analyses were conducted using the PASW Statistics analysis software package (v19.0, Chicago, USA).

\section{Results}

\section{Patient demographics}

One hundred seventy patients were enrolled in this study. The patient characteristics are summarized in Table 1. The mean age was $66.0 \pm 7.7$ years, with an average disease duration of $11.1 \pm 7.5$ years, and $\mathrm{HbA} 1 \mathrm{c}$ of $6.9 \pm 1.0 \%$. The subjects were slightly overweight [body mass index (BMI): $23.7 \mathrm{~kg} / \mathrm{m}^{2}$ ]. The mean values of the parameters of bone metabolism and BMD were normal.

\section{Severity and extent of 25(OH)D deficiency}

The mean $25(\mathrm{OH}) \mathrm{D}$ level of the entire group was $20.0 \pm$ $6.3 \mathrm{ng} / \mathrm{mL}$ (range: $6-38 \mathrm{ng} / \mathrm{mL}$ ). The study patients were divided into two groups: those with a normal $25(\mathrm{OH}) \mathrm{D}$ level ( $\geq 30 \mathrm{ng} / \mathrm{mL}, 8.2 \%$, designated as the normal group), and those with abnormal 25(OH)D levels $(<30 \mathrm{ng} / \mathrm{mL}, 91.8 \%$, 
Table 1. Patient Characteristics.

\begin{tabular}{|c|c|}
\hline Age (years) & $66.0 \pm 7.7$ \\
\hline Body weight (kg) & $58.6 \pm 11.4$ \\
\hline Body mass index $\left(\mathrm{kg} / \mathrm{m}^{2}\right)$ & $23.7 \pm 3.7$ \\
\hline Duration of diabetes (years) & $11.1 \pm 7.5$ \\
\hline Systolic blood pressure (mmHg) & $127.4 \pm 14.1$ \\
\hline Diastolic blood pressure $(\mathrm{mmHg})$ & $72.0 \pm 9.1$ \\
\hline $\mathrm{HbAlc}(\%)$ & $6.9 \pm 1.0$ \\
\hline $\mathrm{FPG}(\mathrm{mg} / \mathrm{dL})$ & $138.5 \pm 32.2$ \\
\hline FPI $(\mu \mathrm{U} / \mathrm{mL})$ & $5.7 \pm 3.6$ \\
\hline HOMA-IR & $2.0 \pm 1.4$ \\
\hline LDL-cholesterol (mg/dL) & $114.0 \pm 33.0$ \\
\hline microalbuminuria $(\mathrm{mg} / \mathrm{g} \bullet \mathrm{Cre})$ & $68.7 \pm 174.5$ \\
\hline creatinine $(\mathrm{mg} / \mathrm{dL})$ & $0.70 \pm 0.16$ \\
\hline eGFR $\left(\mathrm{mL} / \mathrm{min} / 1.7 \mathrm{~m}^{2}\right)$ & $80.6 \pm 18.4$ \\
\hline \multicolumn{2}{|l|}{ Indexes of bone metabolism } \\
\hline 1.25-dihydroxy vitamin $\mathrm{D}(\mathrm{pg} / \mathrm{mL})$ & $51.9 \pm 17.1$ \\
\hline 25-hydroxy vitamin D (ng/mL) & $20.0 \pm 6.3$ \\
\hline intact PTH $(\mathrm{pg} / \mathrm{mL})$ & $21.1 \pm 12.9$ \\
\hline $\mathrm{BAP}(\mathrm{U} / \mathrm{L})$ & $25.1 \pm 9.4$ \\
\hline osteocalcin (ng/mL) & $3.5 \pm 1.7$ \\
\hline s-NTX (nmolBCE/L) & $14.2 \pm 4.5$ \\
\hline u-NTX (nmol BCE/nmol • Cre) & $36.0 \pm 17.0$ \\
\hline homocysteine (mmol/L) & $10.7 \pm 4.0$ \\
\hline pentosidine $(\mathrm{mg} / \mathrm{mL})$ & $0.05 \pm 0.03$ \\
\hline Lumbar BMD (g/cm²) & $0.927 \pm 0.191$ \\
\hline$\%$ of YAM & $90.4 \pm 17.9$ \\
\hline T-score & $-0.9 \pm 1.5$ \\
\hline Femoral neck BMD $\left(\mathrm{g} / \mathrm{cm}^{2}\right)$ & $0.657 \pm 0.116$ \\
\hline$\%$ of YAM & $80.3 \pm 13.3$ \\
\hline T-score & $-1.4 \pm 0.9$ \\
\hline Radial bone BMD $\left(\mathrm{g} / \mathrm{cm}^{2}\right)$ & $0.601 \pm 0.134$ \\
\hline$\%$ of YAM & $87.1 \pm 15.1$ \\
\hline T-score & $-1.6 \pm 1.9$ \\
\hline \multicolumn{2}{|c|}{$\begin{array}{l}\text { Data are mean } \pm \text { SD. } \\
\text { HbAlc: hemoglobin A1c, FPG: fasting plasma glucose, FPI: } \\
\text { fasting plasma insulin, HOMA-IR: homeostasis assessment } \\
\text { model of insulin resistance, LDL: low-density lipoprotein, } \\
\text { eGFR: estimated glomerular filtration rate, PTH: parathyroid } \\
\text { hormone, BAP: bone-specific alkaline phosphatase, s-NTX: } \\
\text { serum n-telopeptide, u-NTX: urine n-telopeptide, BMD: bone } \\
\text { mineral density, YAM: young adult mean }\end{array}$} \\
\hline
\end{tabular}

designated as the vitamin $\mathrm{D}$ abnormal group). The latter group was also subdivided into three subgroups: the severe vitamin D deficiency group [25(OH)D: $<10 \mathrm{ng} / \mathrm{mL}, 2.9 \%$, the deficiency group [25(OH)D: $10-19 \mathrm{ng} / \mathrm{mL}, 47.1 \%]$, and the insufficiency group [25(OH)D: $20-29 \mathrm{ng} / \mathrm{mL}, 41.8 \%$ ] (Figure).

\section{Relationship between 25(OH)D and the markers of bone metabolism and other parameters}

Table 2 lists the correlation coefficients for the relationships between $25(\mathrm{OH}) \mathrm{D}$ and the markers of bone metabolism and variables unrelated to bone metabolism. A univariate analysis showed that $25(\mathrm{OH}) \mathrm{D}$ significantly correlated with intact-PTH $(\mathrm{r}=-0.236 ; \mathrm{p}=0.002), 1.25(\mathrm{OH}) \mathrm{VD}_{2} \quad(\mathrm{r}=$ $0.591 ; \mathrm{p}<0.001)$, s-NTX $(\mathrm{r}=-0.172 ; \mathrm{p}=0.025)$, u-NTX $(\mathrm{r}=$ $-0.222 ; \mathrm{p}=0.013)$, and the radial bone BMD $(\mathrm{r}=0.314 ; \mathrm{p}=$ $0.004)$. Conversely, $25(\mathrm{OH}) \mathrm{D}$ was not found to be correlated with the BMD at the lumbar vertebrae or femoral neck or the renal function status. Additionally, there was no significant correlation between $25(\mathrm{OH}) \mathrm{D}$ and the BMI, the duration of diabetes, HbAlc or homeostasis model assessment- insulin resistance (HOMA-IR).

A multivariate analysis with $25(\mathrm{OH}) \mathrm{D}$ as the dependent variable, and age, gender, intact-PTH, BAP, u-NTX, and radial bone BMD as the independent variables, identified $\mathrm{u}-$ NTX (standardized coefficient $\beta=-0.354, p=0.002$ ) as the only independent and significant determinant of $25(\mathrm{OH}) \mathrm{D}$ (adjusted multiple $\mathrm{R}^{2}=0.113$ ) (Table 3 ).

\section{Receiver-operating characteristics curve of 25(OH)D in the patients with and without radial bone osteo- porosis}

The optimal cutoff value of $25(\mathrm{OH}) \mathrm{D}$ was $18.5 \mathrm{ng} / \mathrm{mL}$ with a sensitivity of $55 \%$, specificity of $62 \%$, and AUC of 0.588 . According to these findings, we divided the patients into two groups, the low $25(\mathrm{OH}) \mathrm{D}$ group $[25(\mathrm{OH}) \mathrm{D}$ : $\leq 18.5$ $\mathrm{ng} / \mathrm{mL}, \mathrm{n}=78]$ and the other $25(\mathrm{OH}) \mathrm{D}$ group [25(OH)D: $>18.5 \mathrm{ng} / \mathrm{mL}, \mathrm{n}=92]$, to investigate bone metabolism and the BMD. The radial bone BMD was significantly lower in the low $25(\mathrm{OH}) \mathrm{D}$ group $\left(0.564 \pm 0.137 \mathrm{~g} / \mathrm{cm}^{2}\right)$ than the other 25 (OH)D group $\left(0.640 \pm 0.118 \mathrm{~g} / \mathrm{cm}^{2}, \mathrm{p}=0.017\right)$. Conversely, the u-NTX tended to be higher in the low 25(OH)D group $(38.7 \pm 18.2 \mathrm{nmol} \mathrm{BCE} / \mathrm{nmol} \cdot \mathrm{Cre})$ than the other $25(\mathrm{OH}) \mathrm{D}$ group $(34.0 \pm 15.8 \mathrm{nmol} \mathrm{BCE} / \mathrm{nmol} \cdot \mathrm{Cre})$, although this difference was not significant $(\mathrm{p}=0.175)$.

\section{Discussion}

Hypovitaminosis D has been described in several countries and different races (4). In Korea, nearly half of the population suffers from some degree of vitamin D deficiency (6). The prevalence of vitamin D deficiency is also high in Japan (up to approximately $50 \%$ ), especially in inactive elderly people compared with their active counterparts, and the prevalence is greatly influenced by the activities of daily living (ADL) (7). Other groups have reported that the serum $25(\mathrm{OH}) \mathrm{D}$ concentrations were less than $20 \mathrm{ng} / \mathrm{mL}$ in $75.7 \%$ of the Japanese population (8). In the present study, the mean concentration of serum $25(\mathrm{OH}) \mathrm{D}$ was $20.0 \pm 6.3 \mathrm{ng} /$ $\mathrm{mL}$, and the prevalence of hypovitaminosis $\mathrm{D}$ was very high at $91.8 \%$ in Japanese postmenopausal women with type 2 diabetes mellitus. Animal studies have demonstrated lower levels of $1,25(\mathrm{OH})_{2} \mathrm{D}_{3}$ in type 2 diabetes mellitus models compared with the respective controls (9). The findings from the present study are similar to those of the previous studies, which showed a high prevalence of hypovitaminosis D in the patients with type 2 diabetes mellitus $(10,11)$. However, other studies reported no difference in the prevalence between type 2 diabetes mellitus patients and the respective controls $(12,13)$. Thus, a more thorough analysis of the exact relationship between $25(\mathrm{OH}) \mathrm{D}$ and type 2 diabetes mellitus must be investigated.

The clinical and pathological significance of these findings remain unclear. The present study did not provide data that can explain the higher prevalence of hypovitaminosis D in the patients with type 2 diabetes mellitus. Previous studies have indicated that the chronic insulin-deficient state 


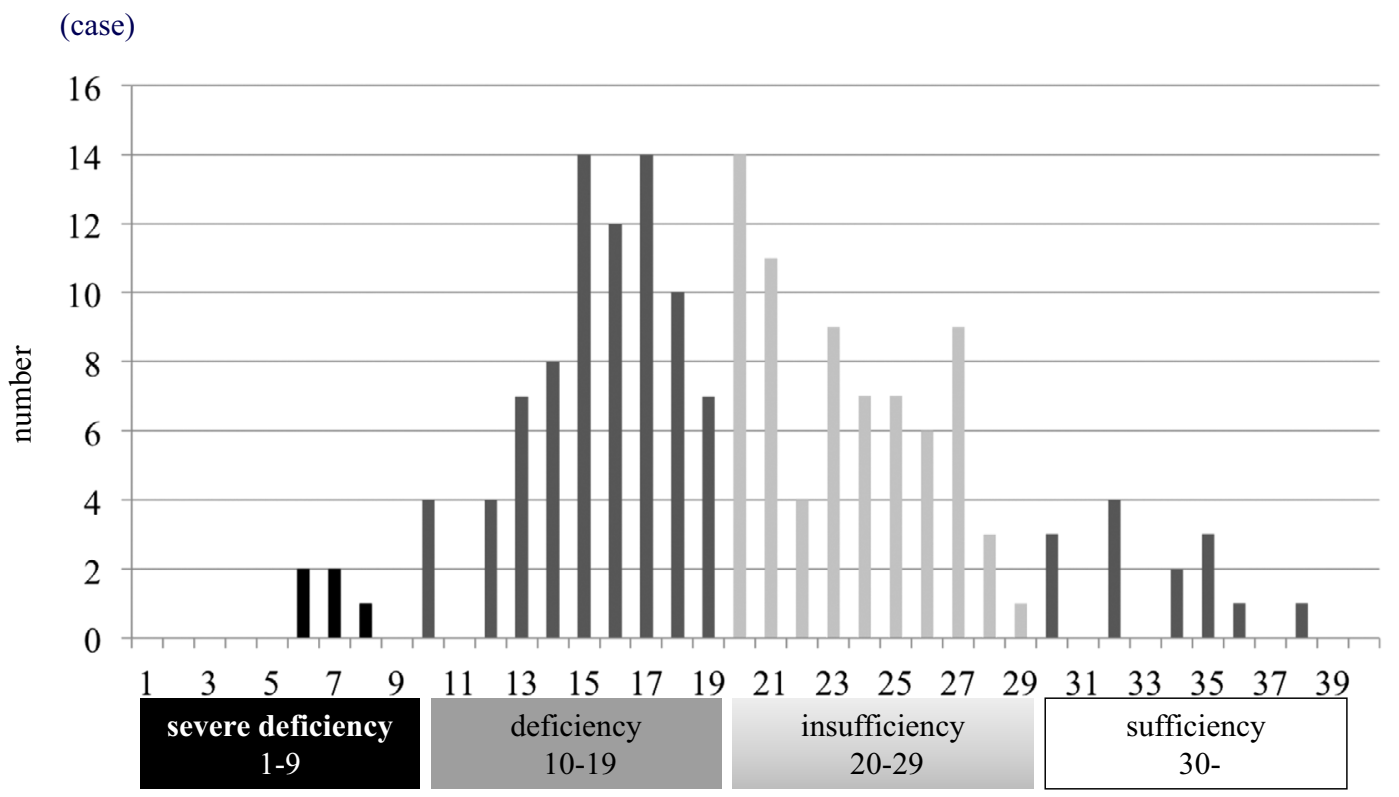

25-hydroxy vitamin $\mathrm{D}(\mathrm{ng} / \mathrm{mL})$

Figure. The frequency distribution of the 25 -hydroxy vitamin $D(\mathrm{ng} / \mathrm{mL})$ level in women with type 2 diabetes mellitus. Solid bars: patients with severe deficiency [25 (OH) D: 1-9 ng/mL], dark gray bars: patients with deficiency [ $25(\mathrm{OH}) \mathrm{D}: 10-19 \mathrm{ng} / \mathrm{mL}$ ], light gray bars: patients with insufficiency [25 (OH) D: 20-29 ng/mL], and open bars: patients with normal levels [25 (OH) D $\geq 30 \mathrm{ng} / \mathrm{mL}$ ].

Table 2. Correlation between 25-hydroxy Vitamin D and Markers of Bone Metabolism as Well as Various Variables Unrelated to Bone Metabolism.

\begin{tabular}{lll}
\hline & $\mathrm{r}$ & $\mathrm{p}$ value \\
\hline Age & -0.005 & 0.952 \\
intact PTH $(\mathrm{pg} / \mathrm{mL})$ & -0.236 & 0.002 \\
eGFR $\left(\mathrm{mL} / \mathrm{min} / 1.7 \mathrm{~m}^{2}\right)$ & 0.017 & 0.855 \\
1.25-dihydroxy vitamin D $(\mathrm{pg} / \mathrm{mL})$ & 0.591 & $<0.001$ \\
BAP $(\mathrm{U} / \mathrm{L})$ & -0.142 & 0.064 \\
osteocalcin $(\mathrm{ng} / \mathrm{mL})$ & -0.196 & 0.120 \\
s-NTX $(\mathrm{nmolBCE} / \mathrm{L})$ & -0.172 & 0.025 \\
u-NTX $(\mathrm{nmolBCE} / \mathrm{nmol} \bullet \mathrm{Cre})$ & -0.222 & 0.013 \\
homocysteine $(\mathrm{mmol} / \mathrm{L})$ & -0.144 & 0.068 \\
pentosidine $(\mathrm{mg} / \mathrm{mL})$ & -0.153 & 0.052 \\
Lumbar BMD $\left(\mathrm{g} / \mathrm{cm}^{2}\right)$ & 0.055 & 0.893 \\
$\quad \%$ of YAM & 0.015 & 0.893 \\
$\quad$ T-score & 0.047 & 0.680 \\
Femoral neck BMD $\left(\mathrm{g} / \mathrm{cm}^{2}\right)$ & 0.043 & 0.738 \\
$\quad \%$ of YAM & -0.042 & 0.744 \\
T-score & -0.023 & 0.858 \\
Radial bone BMD $\left(\mathrm{g} / \mathrm{cm}^{2}\right)$ & 0.314 & 0.004 \\
\% of YAM & 0.242 & 0.030 \\
T-score & 0.222 & 0.047 \\
\hline Data are results of Spearman's & &
\end{tabular}

Data are results of Spearman's rank correlation. Abbreviations as in Table 1.

leads to the reduced 1-alpha-hydroxylase activity and increased 24-hydroxylase activity in chronic streptozotocininduced diabetic rats (14). Other large prospective studies have suggested the potential beneficial effects of both vitamin $\mathrm{D}$ and calcium intake in reducing the risk of type 2 diabetes mellitus $(15,16)$. Further studies are needed to exam- ine the effects of hyperglycemia and insulin resistance on vitamin D metabolism.

Hypovitaminosis D is often asymptomatic and does not require immediate medical care. The analysis of our data showed a significant negative correlation between $25(\mathrm{OH}) \mathrm{D}$ and NTX and intact-PTH. In addition, a a positive correlation between $25(\mathrm{OH}) \mathrm{D}$ and the radial bone BMD was observed. In this regard, previous studies indicated that even a mild reduction in the serum $25(\mathrm{OH}) \mathrm{D}$ level may be associated with secondary hyperparathyroidism, an increased bone turnover, and an accelerated bone loss, which increase the risk of bone fractures $(17,18)$. In the present study, the intact-PTH level was within the normal range. Although high PTH is considered the hallmark of hypovitaminosis D, a "normal" range of PTH may be found in the subjects classified as "vitamin D deficient". Therefore, while many subjects with serum $25(\mathrm{OH}) \mathrm{D}$ levels below the threshold level could have PTH within the "normal" reference range, they may have "functional hyperparathyroidism" $(8,19)$. Thus, hypovitaminosis $\mathrm{D}$ can be regarded as a major risk factor for bone health. Furthermore, we speculate that this relationship increases the risk of fractures of the radius rather than the lumbar spine or femur in the patients with type 2 diabetes mellitus.

The definition of "low" serum $25(\mathrm{OH}) \mathrm{D}$ and vitamin D deficiency depends on the level defined as "normal". Considering the serum level of $25(\mathrm{OH}) \mathrm{D}$ in the "insufficient" range (i.e., 10 to $30 \mathrm{ng} / \mathrm{mL}$ ) is challenging for several reasons. According to the World Health Organization, levels below $20 \mathrm{ng} / \mathrm{mL}$ are classified as abnormal. However, with the recent changes in the laboratory reference range, a normal 
Table 3. Results of Multivariate Analyses with 25-hydroxy Vitamin $D$ as the Dependent Variable.

\begin{tabular}{llllll}
\hline Variables & $\begin{array}{l}\text { Non-standardized } \\
\text { Coefficients }\end{array}$ & $\begin{array}{l}\text { Standardized } \\
\text { coefficient } \beta\end{array}$ & p value & $95 \% \mathrm{CI}$ & \\
\hline Intercept & 26.298 & & $<0.01$ & 22.211 & 30.385 \\
$\mathrm{u}-\mathrm{NTX}$ & -0.162 & -0.354 & 0.002 & -0.264 & -0.059 \\
\hline Adjusted multiple $\mathrm{R}^{2}$ & 0.113 & & & \\
\hline Multivariate stepwise regression analysis with & 25-hydroxy vitamin D as the \\
dependent variable and age, intact-PTH, BAP, u-NTX, radial bone BMD as \\
independent variables. \\
Abbreviations as in Table 1.
\end{tabular}

level of $25(\mathrm{OH}) \mathrm{D}$ is currently defined as a serum level of 30 to $76 \mathrm{ng} / \mathrm{mL}(20,21)$. The optimal serum levels and intake necessary to prevent osteoporosis in the patients with type 2 diabetes mellitus are unknown. In the present study, we used a cutoff value for $25(\mathrm{OH}) \mathrm{D}$ of $18.5 \mathrm{ng} / \mathrm{mL}$ for radial bone osteoporosis. There is substantial variation in the PTH level when the $25(\mathrm{OH}) \mathrm{D}$ levels are between 20 and $30 \mathrm{ng} /$ $\mathrm{mL}$ (22). Thus, according to these results, the patients with $25(\mathrm{OH}) \mathrm{D}$ concentrations $<18.5 \mathrm{ng} / \mathrm{mL}$ are at risk for osteoporosis, indicating that the management of vitamin D is important in preventing osteoporosis in women with type 2 diabetes mellitus. Therefore, the optimal $25(\mathrm{OH}) \mathrm{D}$ concentration relative to osteoporosis should be $\geq 20 \mathrm{ng} / \mathrm{mL}$.

There are some limitations associated with the present study. First, the study sample was relatively small. Second, the study did not include a control group. Third, the variables measured in the present study vary with time of the year, daily activity, and exercise level. Accordingly, further large-scale studies are warranted that include more potentially confounding factors. These future studies should also focus on the effects of low vitamin D status in women with type 2 diabetes mellitus on bone fractures, using appropriate study designs, such as cohort and intervention studies with a sufficient sample size. Such studies should clarify the relationship between hypovitaminosis $\mathrm{D}$ and osteoporosis in type 2 diabetes mellitus and serve to design appropriate management protocols to prevent osteoporosis in the patients with type 2 diabetes mellitus.

In conclusion, our study identified an alarmingly high rate of hypovitaminosis D and vitamin D deficiency among Japanese women with type 2 diabetes mellitus. The present study did not include a control group, which prevented us from concluding that the incidence of vitamin D deficiency was higher in the patients with type 2 diabetes than the general population. Nevertheless, our study identified vitamin D deficiency in many patients with type 2 diabetes.

Vitamin D is important for the mechanical and structural integrity of the skeleton, and hypovitaminosis D can amplify the age-related bone turnover, bone loss from the radius, which is mediated through secondary hyperparathyroidism in women with type 2 diabetes mellitus. Therefore, screening and treating hypovitaminosis D is important in such patients.

\section{Author's disclosure of potential Conflicts of Interest (COI).}

Yoshiya Tanaka: Honoraria, Mitsubishi-Tanabe Pharma, Eisai, Chugai Pharma, Abbott Japan, Astellas Pharma, Daiichi-Sankyo, Abbvie, Janssen Pharma, Pfizer, Takeda Pharma, Astra-Zeneca, Eli Lilly Japan, GlaxoSmithKline, Quintiles, MSD and AsahiKasei Pharma; Research Funding, Bristol-Myers, MitsubishiTanabe Pharma, Abbvie, MSD, Chugai Pharma, Astellas Pharma, and Daiichi-Sankyo.

\section{Acknowledgement}

The authors thank Ms. N. Sakaguchi for her excellent technical assistance. This study was supported in part by a Research Grant-In-Aid for Scientific Research from the Ministry of Health, Labour and Welfare of Japan, the Ministry of Education, Culture, Sports, Science and Technology of Japan, the Joint Research Association for Japanese Diabetes, and the University of Occupational and Environmental Health, Japan.

\section{References}

1. Vestergaard P. Discrepancies in bone mineral density and fracture risk in patients with type 1 and type 2 diabetes: a meta-analysis. Osteoporos Int 18: 427-444, 2007.

2. Schwartz AV, Sellmeyer DE, Ensrud KE, et al. Older women with diabetes have an increased risk of fracture: a prospective study. $\mathrm{J}$ Clin Endocrinol Metab 86: 32-38, 2001.

3. Lips P. Vitamin D deficiency and secondary hyperparathyroidism in the elderly: consequences for bone loss and fractures and therapeutic implications. Endocr Rev 22: 477-501, 2001.

4. Mithal A, Wahl DA, Bonjour JP, et al; IOF Committee of Scientific Advisors (CSA) Nutrition Working Group. Global vitamin D status and determinants of hypovitaminosis D. Osteoporos Int 20: 1807-1820, 2009.

5. Seino Y, Nanjo K, Tajima N, et al. Report of the committee on the classification and diagnostic criteria of diabetes mellitus. J Diabetes Invest 1: 212-228, 2010.

6. Choi HS, Oh HJ, Choi H, et al. Vitamin D insufficiency in Korea: a greater threat to younger generation: the Korea National Health and Nutrition Examination Survey (KNHANES) 2008. J Clin Endocrinol Metab 96: 643-651, 2011.

7. Nakamura K. Vitamin D insufficiency in Japanese populations: from the viewpoint of the prevention of osteoporosis. $\mathrm{J}$ Bone Miner Metab 24: 1-6, 2006.

8. Okazaki R, Sugimoto T, Kaji H, et al. Vitamin D insufficiency defined by serum 25-hydroxyvitamin $\mathrm{D}$ and parathyroid hormone before and after oral vitamin $\mathrm{D}_{3}$ load in Japanese subjects. $\mathrm{J}$ Bone Miner Metab 29: 103-110, 2011.

9. Ishimura E, Nishizawa Y, Koyama H, Shoji S, Inaba M, Morii H. Impaired vitamin D metabolism and response in spontaneously 
diabetic GK rats. Miner Electrolyte Metab 21: 205-210, 1995.

10. Pietschmann P, Schernyhaner G, Woloszczuk W. Serum osteocalcin levels in diabetes mellitus: analysis of the type of diabetes and microvascular complications. Diabetologia 31: 892-895, 1988.

11. Isaia G, Giorgino R, Adami S. High prevalence of hypovitaminosis $\mathrm{D}$ in female type 2 diabetic population. Diabetes Care 24: 1496, 2011.

12. Ishida H, Seino Y, Matsukura S, et al. Diabetic osteopenia and circulating levels of vitamin D metabolites in type 2 (noninsulindependent) diabetes. Metabolism 34: 797-801, 1985.

13. Suzuki A, Kotake M, Ono Y, et al. Hypovitaminosis D in type 2 diabetes mellitus: association with microvascular complications and type of treatment. Endocr J 53: 503-510, 2006.

14. Hough S, Fausto A, Sonn Y, Dong Jo OK, Birge SJ, Aviolo LV. Vitamin D metabolism in the chronic streptozotocin-induced diabetic rat. Endocrinology 113: 790-796, 1983.

15. Pittas AG, Dawson-Hughes B, Li T, et al. Vitamin D and calcium intake in relation to type 2 diabetes in women. Diabetes Care 29: 650-656, 2006.

16. Holick MF. Nutrition: D-iabetes and D-eath D-efying vitamin D.
Nat Rev Endocrinol 8: 388-390, 2012.

17. Adams JS, Hewison M. Update in vitamin D. J Clin Endocrinol Metab 95: 471-478, 2010.

18. Mezquita-Raya $P$, Muñoz-Torres $M$, Luna JD, et al. Relation between vitamin D insufficiency, bone density, and bone metabolism in healthy postmenopausal women. J Bone Miner Res 16: 1408$1415,2001$.

19. Souberbielle JC, Lawson-Body E, Hammadi B, Sarfati E, Kahan $\mathrm{A}$, Cormier $\mathrm{C}$. The use in clinical practice of parathyroid hormone normative values established in vitamin D-sufficient subjects. J Clin Endocrinol Metab 88: 3501-3504, 2003.

20. Rosen CJ. Clinical practice. Vitamin D insufficiency. N Engl $J$ Med 364: 248-254, 2011.

21. Grundmann M, von Versen-Höynck F. Vitamin D: roles in women's reproductive health? Reprod Biol Endocrinol 2: 146, 2011.

22. Steingrimsdottir L, Gunnarsson O, Indridason OS, Franzson L, Sigurdsson G. Relationship between serum parathyroid hormone levels, vitamin D sufficiency, and calcium intake. JAMA 294: 2336-2341, 2005.

(C) 2015 The Japanese Society of Internal Medicine http://www.naika.or.jp/imonline/index.html 